\title{
Is There a Standard for the Palliative Treatment of Melanoma?
}

\section{Schadendorf}

Skin Cancer Unit of the German Cancer Research Center at the Department of Dermatology, University Hospital Mannheim

Evidence-based medicine (EBM) is a thorough, explicit and rationale use of all the best available external scientific evidence in the medical care for individual patients (adapted from: Sackett DL, et al: Münch Med Wochenschr 1997;139:644-645).

\section{Introduction}

Melanoma continues to present a major therapeutic challenge to oncologists, oncological surgeons and dermatologists with rapidly rising incidence over recent decades. 10 melanomas per 100.000 inhabitants are newly diagnosed per year in Europe. Only early detection and adequate surgical excision of the primary tumor will prevent metastatic dissemination. Around $20 \%$ of affected patients will eventually develop metastases and die of melanoma. Current therapeutic concepts were recently reviewed [1]. No effective curative treatment is available in stage IV of this disease. In its metastatic stage, melanoma is highly resistant to standard forms of therapy (e.g. surgery, chemotherapy) [2, 3]. Polychemotherapy and/or combination with cytokines did not demonstrate superiority to single-agent dacarbacine (DTIC) which is still considered standard treatment in Europe. This paper reviews randomized-controlled clinical trials performed over the last 25 years that applied cytotoxic agents in advanced melanoma.

\section{Randomized Trials with Cytotoxic Agents Only}

Systemic therapies for metastatic cutaneous melanoma have achieved only a few lasting remissions and the therapeutic aim remains one of palliation. In a recent Cochrane review of melanoma treatment in stage IV no evidence from randomized controlled clinical trials was found to demonstrate superi- ority of systemic therapy over best supportive care / placebo [4]. However, around 1.500 metastatic patients have been treated in 9 randomized trials comparing various DTIC-containing chemotherapy regimens with each other in studies accruing between 69 and up to 386 patients. 4 of the trials compared DTIC alone versus polychemotherapy regimens. Clinical response rates (RRs) of DTIC alone ranged between 9.9 and $18 \%$, depending on the number of patients included in the treatment arm. RR were increased in several instances where chemotherapy combinations were used and which mostly included DTIC as well, however, median survival was not affected in all 9 randomized trials. RRs and overall survival were analyzed in a recent meta-analysis of 3,273 patients from 20 randomized trials that was performed comparing single-agent DTIC to combination chemotherapy with or without immunotherapy [5]. Although the analysis showed an increased odds ratio (OR) suggesting that combination drug therapies were associated with a certain increase in RR compared with single-agent DTIC, no survival benefit was detected. In a recently published report, the Dartmouth regimen, a treatment schedule widely used in the USA containing DTIC, BCNU, cisplatin and tamoxifen (TMX), was compared to DTIC alone in 240 patients by Chapman and co-workers [6]. Median survival time from randomization was 7 months and no difference in survival time between the two treatment arms was detected, however, bone marrow suppression, nausea/ vomiting, and fatigue were significantly more common in the Dartmouth arm. In the recently reported trial DTIC was compared with temozolomide, a newly developed substance which can be given orally and has the capacity to penetrate the brain-blood barrier. 305 patients were randomized. RRs were around $13 \%$ and median survival times ranged around 7 months in both groups. Median progression-free survival time was significantly longer in the temozolomide-treated group (1.9 months) than in the DTIC-treated group (1.5 months) [7].

\begin{tabular}{ll}
\hline KARGER & @ 2002 S. Karger GmbH, Freiburg \\
$\begin{array}{l}\text { Fax +497614520714 } \\
\begin{array}{l}\text { E-mail Information@Karger.de } \\
\text { www.karger.com }\end{array}\end{array}$ & Accessible online at: \\
& www.karger.com/journals/onk
\end{tabular}

Prof. Dr. Dirk Schadendorf

Klinische Kooperationseinheit für Dermanto-Onkologie (DKFZ) Klinikum Mannheim

Theodor-Kutzer Ufer-1, D-68135 Mannheim (Germany)

Tel. +49 621-383 2127, Fax -2163

E-mail d.schadendorf@dkfz.de 


\section{Randomized Trials with Cytotoxic Agents and Tamoxifen}

At least 5 randomized studies were performed testing the beneficial effect of TMX. Based on the hypothesis that endocrine factors may affect the clinical course of melanoma and the response to the treatment of this disease a first randomized trial was initiated in 117 patients comparing DTIC with DTIC plus TMX by Cocconi et al. [8] demonstrating overall RR statistically higher (28 vs. 12\%). Unfortunately, the effect of TMX was not reproducible in 3 subsequent trials. Rusthoven et al. [9] reported on a randomized, double-blind, placebo-controlled trial to compare the RR and survival of melanoma patients who had received the Dartmouth regimen (BCNU, DTIC, cisplatin, TMX) or the same triple chemotherapy with placebo. 211 patients were accrued, the overall RR were statistically not different in agreement with subsequent data reported by Chapman et al. [5]. In a randomized $2 \times 2$ factorial design to receive one of the 4 treatment arms [DTIC alone, DTIC plus interferon (IFN), DTIC plus TMX, and DTIC plus IFN plus TMX], 261 patients were included in a study performed by Falkson (1998) [10]. 9 complete remissions (CRs) and 18 partial remissions (PRs) were observed in the patients who received treatments that contained IFN compared with 4 CRs and 18 PRs in the patients who received treatments that did not contain IFN. 5 CRs and 20 PRs occurred in patients treated with TMX compared with 8 CRs and 16 PRs in those treated without TMX. Response differences were non-significant. There was no significant difference in survival time among any of the different groups. Significantly more severe and life-threatening toxic events occurred with treatments that contained IFN.

\section{Randomized Trials with Cytotoxic Agents and Cytokines}

Several randomized studies were performed testing the beneficial effect of IFN. A decade ago, Falkson et al. [11] reported on a two-arm study comparing DTIC versus DTIC plus IFN in only 64 patients suggesting a significant better RR in the IFNtreated patients $(53 \%)$ than in the DTIC alone arm $(20 \%)$. These results could not be reproduced in a number of controlled randomized trials including ones by Falkson and her group [10].

IFN was tested not only in combination with cytotoxic drugs but also in combination with high-dose intravenous bolus interleukin-2 (IL-2) versus high-dose IL-2 alone in 85 patients. There was no significant difference in the median survival duration (around 10 months). The authors concluded that IFN failed to enhance significantly the response rate to high-dose IL-2 in the treatment of patients with advanced melanoma. Adding cisplatin to both arms (as recently published) did not change overall survival time and RR significantly [12].
Whether a combination of IFN and high-dose IL-2 plus/minus cisplatin is active in metastatic melanoma was asked by Keilholz et al. [13]. 138 patients were accrued for the trial. The objective RR was $18 \%$ without and $33 \%$ with cisplatin ( $\mathrm{p}=$ 0.04 ), but there was no statistically significant difference in survival between treatment arms. The effect of adding IFN and IL-2 to chemotherapy was also addressed by Rosenberg et al. [14]. 102 patients were prospectively randomized to receive chemotherapy composed of DTIC, TXM and cisplatin, or this same chemotherapy followed by IFN and IL-2. In patients randomized to receive chemotherapy, 14/52 objective responses $(27 \%)$ were observed, in comparison to $22 / 50$ objective responses $(44 \%)$ in patients randomized to receive chemoimmunotherapy,. In both treatment groups, the duration of partial responses was often short, and there was a trend toward a survival advantage for patients receiving chemotherapy alone. Treatment-related toxicities were greater in patients receiving chemoimmunotherapy. The German Melanoma Study Group (DeCoG) asked for the benefit of IL-2 in combination with DTIC and IFN [15]. 290 patients were randomized and no difference in terms of survival time from treatment onset between the two arms (median 11.0 months each) was detected. RR did not differ between both arms with $18.0 \%$ objective responses for DTIC plus IFN-alpha as compared to $16.1 \%$ for DTIC, IFN-alpha and IL-2.

The above quoted meta-analysis based on more than 3,500 patients came to the conclusion that the combination of DTIC plus IFN produced an increased RR than that observed with DTIC alone. This increase was greater than that seen with DTIC-containing multi-drug regimens. Unfortunately, no difference in overall survival was demonstrated.

\section{Conclusion}

A recent Cochrane review states that no trial has been performed to demonstrate the beneficial effect of chemotherapy in metastatic melanoma compared to best supportive care [4]. Since it is currently unclear whether any combination therapy for the treatment of metastatic melanoma is superior to standard single-agent DTIC in terms of RR and overall survival, single-agent DTIC remains the gold standard for advanced melanoma in first-line treatment.

Whether novel treatment approaches such as the modulation of drug resistance by infusing antisense oligonucleotides targeted against bcl-2 mRNA to increase melanoma cell apoptosis and subsequently leading to improve tumor responses and overall survival times in combination with DTIC, is currently under investigation in a worldwide prospective-randomized registration trial. Results are expected early in 2003. A second glimpse of hope in the palliative treatment of advanced melanoma is a recent multicenter study led by Agarwala [16] which suggests that histamine dihydrochloride exhibits unexpected clinical benefits in patients with metastatic 
melanoma of the liver, thus achieving for the first time a significant survival advantage for metastatic melanoma patients using a combination of histamine and IL-2 in comparison to patients treated with IL-2 alone. Wordwide there is a confirmatory registration trial currently under preparation which is supposed to start in early 2002. Similar successes are also been expected by various vaccination approaches aiming at the induction of cellular (and humoral) immune response. However, most of these studies are still on a phase I/II level and industrial support is missing. Older vaccininations employing whole tumor vaccines have not been tested in prospective randomized fashion (reviewed in [17]). Only one prospective-randomized clinical phase II/III trial comparing DTIC alone versus peptide-pulsed autologous dendritic cells is ongoing in Germany and supported by the German Cancer Aid. Results are expected in 2-3 years.

Last but not least, second-line chemotherapy in advanced melanoma is frequently performed, however, no randomized controlled phase II or III study has so far been performed.

Is there a standard for the palliative treatment of melanoma? Based on the evidence-based criteria outlined above, patients suffering from all stages of advanced melanoma should only be entered into controlled prospective (randomized) clinical protocols in the first- and second-line situation to improve the current situation in the long-term for the sake of our patients.

\section{References}

1 Tilgen W: Malignant melanoma. Curr Ther Concepts 1995:18:534-547.

2 Helmbach H, Rossman E, Kern MA, Schadendorf D: Drug-resistance in human melanoma. Int J Cancer 2001;93:617-622.

3 Berger W, Elbing L, Mischke M: Chemoresistance of human malignant melanoma: Cellular and molecular aspects. Onkologie 1998;21:105-110.

4 Crosby T, Fish R, Coles B, Mason MD: Systemic treatments for metastatic cutaneous melanoma (Cochrane Review); in The Cochrane Library, 4, 2001. Oxford: Update Software.

5 Huncharek M, Caubet Jf, Mcgarry R: Single-agent DTIC versus combination chemotherapy with or without immunotherapy in metastatic melanoma: A meta-analysis of 3273 patients from 20 randomized trials. Melanoma Res 2001;11:75-81.

6 Chapman PB, Einhorn LH, Meyers ML, Saxman S, Destro AN, Panageas KS, Begg CB, Agarwala SS, Schuchter LM, Ernstoff MS, Houghton AN, Kirkwood JM: Phase III multicenter randomized trial of the Dartmouth regimen versus dacarbazine in patients with metastatic melanoma. J Clin Oncol 1999;17:2745-2751.

7 Middleton Mr, Grob Jj, Aaronson N, Fierlbeck G, Tilgen W, Seiter S, Gore M, Aamdal S, Cebon J, Coates A, Dreno B, Henz M, Schadendorf D, Kapp A, Weiss J, Fraass U, Statkevich P, Muller M, Thatcher N: Randomized phase III study of temozolomide versus dacarbazine in the treatment of patients with advanced metastatic malignant melanoma. J Clin Oncol 2000;18:158-166. Erratum in J Clin Oncol 2000;18:2351. Comment in J Clin Oncol 2000;18: 2185.

8 Cocconi G, Bella M, Calabresi F, Tonato M, Canaletti R, Boni C, Buzzi F, Ceci G, Corgna E, Costa P, et al.: Treatment of metastatic malignant melanoma with dacarbazine plus tamoxifen. N Engl J Med 1992;327:516-523. Comments in: N Engl J Med 1992;327:560-561. Comments in New Engl J Med 1993;328:140-141.
9 Rusthoven JJ, Quirt IC, Iscoe NA, Mcculloch PB, James KW, Lohmann RC, Jensen J, Burdette-Radoux S, Bodurtha AJ, Silver HK, Verma S, Armitage GR, Zee B, Bennett K: Randomized, doubleblind, placebo-controlled trial comparing the response rates of carmustine, dacarbazine, and cisplatin with and without tamoxifen in patients with metastatic melanoma. National Cancer Institute of Canada Clinical Trials Group. J Clin Oncol 1996:14: 2083-2090.

10 Falkson CI, Ibrahim J, Kirkwood JM, Coates AS, Atkins MB, Blum RH: Phase III trial of dacarbazine versus dacarbazine with interferon alpha- $2 b$ versus dacarbazine with tamoxifen versus dacarbazine with interferon alpha-2b and tamoxifen in patients with metastatic malignant melanoma: An Eastern Cooperative Oncology Group study. J Clin Oncol 1998;16:1743-1751.

11 Falkson CI, Falkson G, Falkson HC: Improved results with the addition of interferon alfa- $2 b$ to dacarbazine in the treatment of patients with metastatic malignant melanoma. J Clin Oncol 1991;9: 1403-1408.

12 Dorval T, Negrier S, Chevreau C, Avril MF, Baume D, Cupissol D, Oskam R, De Peuter R, Vinke J, Herrera A, Escudier B: Randomized trial of treatment with cisplatin and interleukin-2 either alone or in combination with interferon-alpha-2a in patients with metastatic melanoma: A Federation Nationale des Centres de Lutte Contre le Cancer Multicenter, Parallel Study. Cancer 1999;85:1060-1066.

13 Keilholz U, Goey SH, Punt CJ, Proebstle TM, Salzmann R, Scheibenbogen C, Schadendorf D, Lienard D, Enk A, Dummer R, Hantich B, Geueke AM, Eggermont AM: Interferon alfa-2a and interleukin-2 with or without cisplatin in metastatic melanoma: A randomized trial of the European Organization for Research and Treatment of Cancer Melanoma Cooperative Group. J Clin Oncol 1997; 15:2579-2588.
14 Rosenberg SA, Yang JC, Schwartzentruber DJ, Hwu P, Marincola FM, Topalian SL, Seipp CA, Einhorn JH, White DE, Steinberg SM: Prospective randomized trial of the treatment of patients with metastatic melanoma using chemotherapy with cisplatin, dacarbazine, and tamoxifen alone or in combination with interleukin-2 and interferon alfa-2b. J Clin Oncol 1999:17:968-975.

15 Hauschild A, Garbe C, Stolz W, Ellwanger U, Seiter S, Dummer R, Ugurel S, Sebastian G, Nashan D, Linse R, Achtelik W, Mohr P, Kaufmann R, Fey $\mathrm{M}$, Ulrich J, Tilgen W: Dacarbazine and interferon alpha with or without interleukin 2 in metastatic melanoma: A randomized phase III multicentre trial of the Dermatologic Cooperative Oncology Group (DeCOG). Brit J Cancer 2001;84:10361042.

16 Agarwala SS, Glaspy J, O’Day SJ, Mitchell M, Gutheil J, Whitman E, Gonzalez R, Hersh E, Feun L, Belt R, Meyskens F, Hellstrand K, Wood D, Kirkwood JM, Gehlsen KR, Naredi P: Results from a randomized phase III study comparing combined treatment with histamine dihydrochloride plus interleukin-2 versus interleukin-2 alone in patients with metastatic melanoma. J Clin Oncol 2002;20: 125-133.

17 Sun Y, Paschen A, Schadendorf D: Cell-based vaccination against melanoma-background, preliminary results, and perspective. J Mol Med 1999:77: 593-608. 